\title{
Personal Learning Environments in Future Professionals: Nor Natives or Residents, Just Survivors
}

\author{
Paz Prendes, Linda Castañeda, Isabel Gutiérrez, and M. Mar Sánchez
}

\begin{abstract}
This work is a brief view of an exploratory research about Personal Learning Environments developed during these last three years with a Spanish sample. Understanding of PLE can help us to improve our learning designs in order to better development of professional competences of students. Thus, we have implemented a questionnaire with $\mathbf{2 . 0 5 4}$ final answers of Spanish university students in last course of their degrees. The questionnaire has been previously validated with a mixed methodological approach based on the use of experts, cognitive interviews and a pilot survey. In the end, we can summarize the main results explaining that our Spanish senior students are very different from the extended idea of digital natives. By the opposite, the majority of them are traditional students who prefer common agendas of paper, make notes on paper and use the Internet overall to search but not to create or share.
\end{abstract}

Index Terms-Personal learning environments, university, exploratory research.

\section{INTRODUCTION}

The evolution of the Internet has been changing our lives during these last decades and moreover our models of teaching and learning. Currently the information and the communication are core in our life and in our behavior so research about how we use them to learn is very relevant and this is the principal sense of this research project centered on Personal Learning Environments of university students.

The concept of Personal Learning Environment (from here on, PLE) is relatively new in the field of educational research but we can easily see conceptual connections between this concept and the well-known studies about learning styles, individual differences, self-regulated learning, personalized education or social learning. It is also true that PLE approach is linked to other aspects as personal networks and the impact of the Internet in our processes of learning. So we can understand PLE as a summary of different concepts that try to explain how students learn and that is the core of our research.

As teachers, we consider that the knowledge about the PLE of our students could help us to improve our learning designs in order to understand how the outcomes can be better arrived. And moreover these learning designs can consider the long-life learning competence as an important objective in the training of our students. PLE can certainly show us an approximation to acquired competences in order to show the

Manuscript received September 12, 2015; revised December 28, 2015. This work was totally supported by the Spanish Ministry of Economy and Sustainability for four years, from 2013 to 2016 (Project Reference EDU2012-33256). Further information about the project: www.um.es/ple.

The authors are with University of Murcia, Spain (e-mail: pazprend@um.es). future of the learners in the process of their permanent learning process in their future professional context.

\section{STATE OF THE ART}

Learning is a process that not only happens inside the classrooms but also outdoors, so the students are always learning in formal, no formal and informal situations. In this sense, informal ways of learning are every day more important thanks to the influence of technologies [1]. Being this idea our starting point, we center our interest in the Personal Learning Environment, a relative new concept that has been conceptualized by different authors from diverse theoretical approaches [2]-[5].

According to the literature [2], [5]-[11], there are interesting approaches to the concept of PLE and his practical implications. The broad use of the term is sometimes equated with "a set of tools, data sources, connections and activities (experiences) that each person use habitually to learn" according to [12]. For [13] the crucial components of PLE are strategies and tools and strategies for reading, for writing and finally for sharing. Potentially, every people could include, organize and manage their informal, formal and non-formal learning resources, tools and experiences [2]-[4], [10] in order to expand their learning opportunities.

Throughout this paper we are going to understand the concept of PLE from this approach including telematic tools to learn (technological part of the PLE) and also strategies to manage information (educational part of it). Moreover we can understand that this concept includes a personal process of learning but also a social process (understood as Personal Learning Network, PLN). At the same time, we cannot forget that learning is a process not always technologically supported, so in the end the PLE is a pedagogical approach with a strong technological support.

These previous studies have defined the concept of PLE but there are no data about real PLE of our students thus it is the focus of our research project that we explain next.

In relation to the framework of how students learn we can remember also the idea of digital natives versus digital immigrants [14]. The author arguments that "our students have changed radically" and this idea is the beginning of his theory about the new learner that thinks and process information not at the same mode as previous learners -not born in ICT era-. This new cognitive processes are directly connected to ICT uses. Digital natives use technologies to communicate, study, play... or any other normal activity in their lives. The author continues explaining that they are consumers of video and multimedia so they prefer this formats to texts. At least, they also use technologies to create 
and share digital contents.

Afterwards we can found the model of [15] who consider that it is no relevant the date of birth although it is important the time we spend on the net and time using ICT. Everyone can be "resident" if lives on line, so residents use technology ordinarily both for personal and professional behaviors. By the opposite the visitor uses technologies sometimes and he does not need to live on line all time.

\section{OUR RESEARCH PROJECT: CAPPLE}

CAPPLE is the Spanish acronym of "Competencias para el Aprendizaje Permanente basado en el uso de PLEs: análisis de los futuros profesionales y propuestas de mejora", that is in English "PLEs based lifelong learning skills: analysis of future professionals and suggestions for improvement". It is a national funded project in which we attempt to describe and analyse the prospects for the personal learning environments (PLEs) of future professionals. It includes the analysis of this in technical and functional terms, learning strategies, experiences, resources and tools associated. The project is studying professionals with potentially an immediate incorporation into the labour market of every area of knowledge, in other words, senior students in universities or vocational training [16]-[18].

The principal objective of the project is clarify how students learn and how is their environment to learn, an environment that is always changing and probably could help them in the long life learning processes as professionals in the future. Consequently, we understand that formal learning must offer to students opportunities to build the knowledge but also to provide tools (technological, practical and cognitive) in order to be useful for their future lives.

Specifically, in this research we focus on the study of educational practices (learning practices, to be precise) of future Spanish professionals (currently senior university students). We are going to analyze their practices to learn, and from those practices, we want to explore the empirical and analytical relationships that could exist and would allow us to draw some inferences about these particular realities in the broader scope of our study group.

Therefore, with the description and analysis of the current PLEs of future professionals, we want to know what these environments are like. In addition, we want to understand what these environment features are, as well as the kind of strategies students have been using to organize them. We also want to know if some of these strategies come from formal learning, and if not, what kind of lack of transversal learning made them evident.

All this information allow us to better understand the processes of creation, management and enrichment process related to PLEs, as well as to better knowing the strategies to improve these processes in formal education. Not in vain, we understand PLEs are key elements of citizen's learning development, as well as a crucial part of a citizen's digital identity and life long learning competence.

\section{ReSEARCH METHOD}

This research has been carried out based on a mixed approach [19], [20]. Thus we have used a non-experimental quantitative approach in which we try to describe, compare, and correlate the strategies and tools used by future Spanish professionals to learn combined with a non-interactive qualitative approach, in which we also intend to analyze and understand how these strategies and tools are configured, in specific models of personalized learning environments -one for each person probably, and can also explain more generalized trends, associating some to the learner characteristics-. According to [21], this mixed methodology has some advantages like the chances to triangulate data and also the options to deploy the objectives. These both aspects are especially helpful in the case of complex processes that must be unraveled for a better understanding as this specific case of self-regulated learning processes and personal learning environments.

\section{A. Objectives}

This exploratory research has as main objectives the following:

1) To describe strategies and tools used by senior university students from all areas of knowledge to enrich and manage their learning -inside and outside the classroom-, but specially those that take place in online contexts.

2) To analyze the results and profiles in relation to gender and global areas of knowledge (Sciences, Health, Social Sciences \& Law, Arts \& Humanities and last Engineering $\&$ Arquitecture).

3) To develop a telematic tool to obtain a diagram with the answers to the questionnaire in order to compare or also to facilitate self-perception about PLE of every student.

4) To provide useful information to universities about how our students learn and how to improve their long-life learning competences.

These objectives will provide us a framework to develop future projects in relation of this first exploratory research.

\section{B. Phases of the Process}

This research has 4 phases shown in Fig. 1. The first step was the design and validation of our principal instrument to collect data in a national survey. To identify the relevant information we used the previous revision of the state of the art and after the work of experts that were progressively selecting the information to organize the items. After in the second phase we are analyzing all the information recollected with the final survey with more than 2000 university Spanish students. At the same time we are designing and developing a diagrammer, a telematic tool to describe and compare the results found in the data. In the end, we intend to analyze and explore educational and institutional implications proposing practical advices for our high level system. These proposals will be based on both pedagogical and organizational development in the University.

After the survey design, the validation of the instrument was carried out in a process based on different proceedings (Fig. 2):

1) Expert's review. A final review of the elements and categories included in the survey, as well as the scales and structure of it.

2) Cognitive Interviewing. As [22] remarks, "cognitive 
interviewing has been developed determining whether respondents comprehend questions as by the survey sponsor, and whether questions can be answered accurately". It is a very simple technique that can give us a lot of information to guarantee that people is going to answer regarding the information we want to explore. The interview was completed by 24 senior students from 5 different universities in Spain and of different degrees. The technique to select participants was not probabilistic.

3) Pre-test Piloting. The questionnaire was completed by 400 students (268 female and 132 male with ages covered from 20 until 34 years old). In the sample there were participants from 8 Spanish universities distributed in the 5 areas of knowledge described by the Spanish Ministry of Education: Arts and Humanities, Science, Health Sciences, Social Sciences and Law and Engineering and Architecture.

4) A factor analysis to reinforce the validity and reliability of the questionnaire elements related to its theoretical bases. We wanted to know how every item provided information relative to the categories of the model. Also, in this analysis we found a high experimental mortality for the high number of items. Finally, with the information obtained we created the last version of the questionnaire.

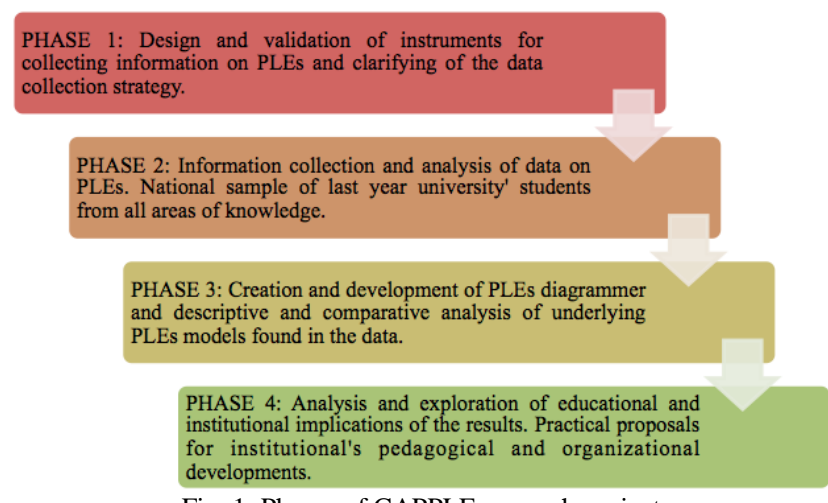

Fig. 1. Phases of CAPPLE research project.

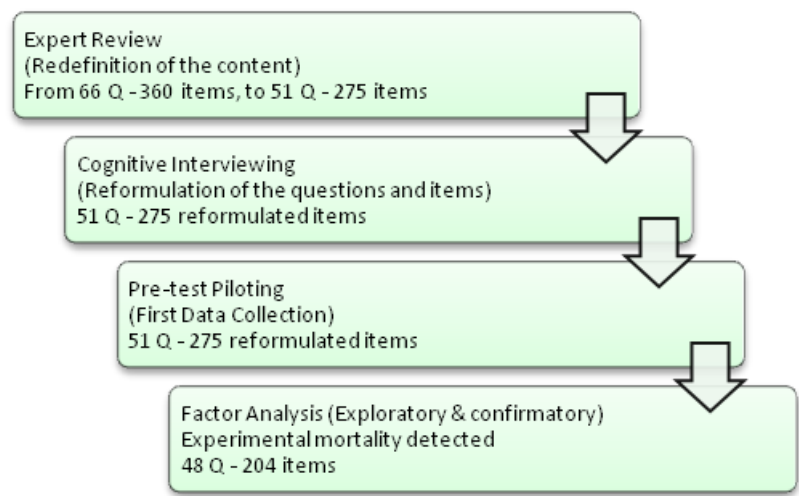

Fig. 2. Validation process of the questionnaire.

In this point we want to emphasize that we do not understand the goal of this project in developing a model catalogue of desirable PLEs nor good PLEs, but to try to analyze what models of PLE are among our senior university students as future professionals and, from them, to explain what this means in the face of formal training.

After analyzing data, the last phase of the research will be the creation of an on line tool to make diagrams as graphical representations of PLE obtained with the questionnaire which will be always on line. According with [23], the iconic representations of PLE contribute to "translucence" understood as "a graphical representation of a virtual space, containing the users of such application as well. As a consequence, PLE visualization should help the learner to understand how his/her community is interacting at any given instant”.

\section{Instrument to Collect Information}

Data were collected using a questionnaire on line. The last version of the questionnaire has 48 questions composed of 59 items. We have reduced 3 questions and 216 items, understanding that these questions and items had been included in other parts of the questionnaire and in order to reduce the experimental mortality detected in the pilot survey. The complex process of validation that we have described above provides us the reliability and confidence in order to know the cognitive strategies and process through different tools that university students are already using.

All items are organized in four great dimensions: self-perception, management of the information, management of the learning process and communication. Inside each dimension all the aspects relative to PLE are integrated with different items (see Fig. 3). It is important to remark that not all the dimensions are equally represented in the final version of the questionnaire (the representation of the dimensions in the final questionnaire is represented in Fig. 4).

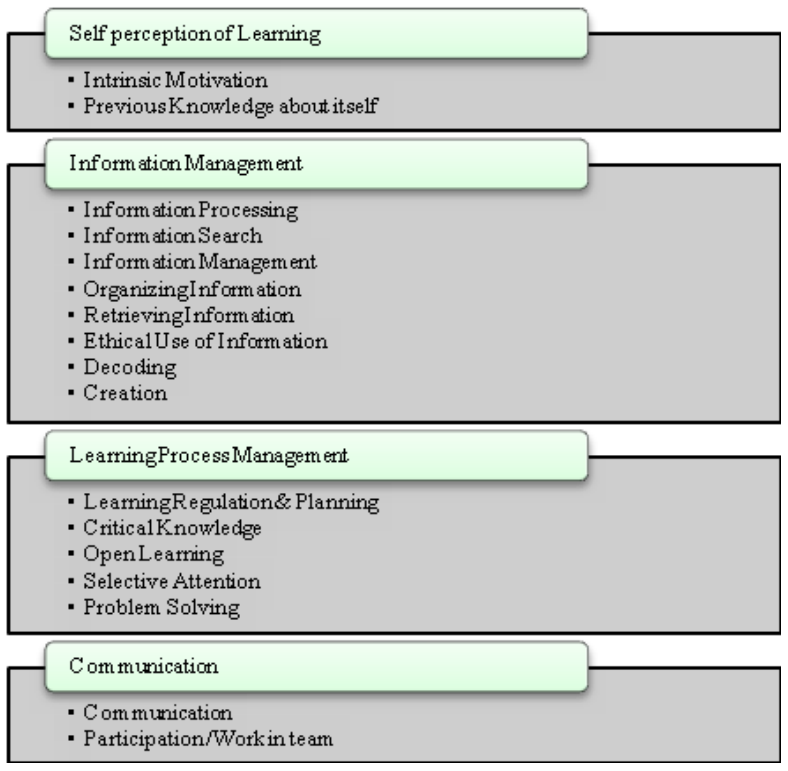

Fig. 3. Dimensions included in our questionnaire.

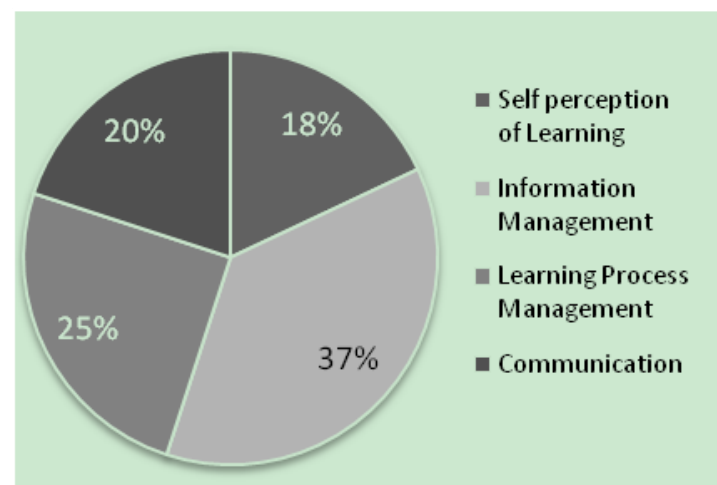

Fig. 4. PLE dimensions weight in the final version of the questionnaire 


\section{Population and Sample}

The context of this research is the ensemble of students of the last year of degree in all the Spanish universities (a total of 75), both public and private. Taking into account the difficulties in accessing to the whole population to guarantee a random sample, one of the most challenging decision of this project has been the way of collecting as much sample as possible. And for this purpose, the research team decided to ask to the whole population using all the communication channels available (Twitter, Email, Website, etc.).

After 6 months of data collection process, we have collected a total of 2054 complete answered questionnaires $(69.67 \%$ women and $30.33 \%$ men) recollected in 38 universities in all the regions of the country, both public and private (the total amount of filled questionnaires is 4399 in 52 universities). The relationship between population and sample of senior Spanish students and its distribution by areas of knowledge is shown in Table I.

TABLE I: SENIOR STUdENTS POPULATION IN SPAIN AND SAMPLE

\begin{tabular}{|c|c|c|c|c|}
\hline $\begin{array}{l}\text { Area of } \\
\text { Knowledge }\end{array}$ & $\begin{array}{l}\text { Senior } \\
\text { Students }\end{array}$ & $\begin{array}{l}\text { Senior } \\
\text { Students } \\
\text { percentage }\end{array}$ & $\begin{array}{l}\text { Sample } \\
\text { number }\end{array}$ & $\begin{array}{l}\text { Sample } \\
\text { percentage }\end{array}$ \\
\hline $\begin{array}{l}\text { Social Science \& } \\
\text { Law }\end{array}$ & 153952 & 52,2 & 879 & 42.79 \\
\hline $\begin{array}{l}\text { Engineering \& } \\
\text { Arquitecture }\end{array}$ & 78265 & 26,5 & 277 & 13,49 \\
\hline Arts \& Humanities & 19966 & 6.8 & 308 & 15 \\
\hline Health & 29844 & 10,1 & 352 & 17.14 \\
\hline Sciences & 16044 & 5.4 & 238 & 11.59 \\
\hline Total & 295067 & 100 & 2054 & 100 \\
\hline
\end{tabular}

Considering that this is a questionnaire with more than 200 items, this is an impressive figure that places this study in a privileged position not only in order to describe the PLE trends and profiles on the population, but moreover in proposing possible research hypotheses, that allow us to deepen the study of the PLE.

\section{RESUlTS}

As we have explained our questionnaire has four dimensions and we are going to present the most important obtained results organized in these categories.

\section{A. Self-perception}

This dimension includes motivation and previous knowledge as principal sub-categories on this category.

Students were asked about what they consider the most valuable resource to learn, and the results show that they value face-to-face classes as an important aspect always or frequently, in order to motivate learning processes $(77.34 \%$ of students). As a second factor in importance, students value the reading in traditional support (63.24\% of students) more than digital information on line (news, forums, chats, Blogs, Twitter, Social Networking Sites, Instant Messaging, and so on). Almost half of students $(45.8 \%)$ don't show relevant interest on seminars or conferences, in parallel to their classes. Furthermore a wide majority of them $(85.49 \%)$, remarks that one important aspect of the academic tasks is knowing a clear objective to understand well the expected outcome of each work.

\section{B. Information Management}

In order to identify how our Spanish students manage information, the survey asked for aspects related to information processing, searching, management, recovering, decoding, creating and in the end the ethic aspects in relation to information.

In seems interesting to confirm that students obviously like using the Internet to search information (almost all of them, $98,29 \%$ ), nonetheless, $60 \%$ of them only use one search engine (not specialized, neither contrasting). Additionally, they do not like the Internet to practice or repeat learning tasks in order to develop their skills.

Despite the factor that they do not prefer any Internet tool as the principal source of information (more than $60 \%$ don't use them), the most used online source of information is Wikipedia (55.02\%). Participants are not taking advantage of social networking sites neither of mobile devices to learn. Furthermore, students prefer reading information more than create or publish online content (almost $24 \%$ of students declare they do not produce ANY online content).

To manage the information they prefer files in traditional formats $(94.69 \%)$ instead of multimedia or hypertext (less than $20 \%$ in every case). To save information our students do not use the cloud (only $15.29 \%$ use it always or frequently), so they prefer their own physical units like the hard disk of the computer, external drivers or pens $(92.5 \%)$.

When the subjects are studying, they declare that paper is encore more relevant than computer to make notes, design, draw and organize iconic representations of knowledge and as a helpful tool to link ideas and concepts. In the same way, when they find relevant information, they download the document and they print or save it $(60.47 \%)$, so they do not use the document on line as usual. When the information is video or multimedia they prefer to make notes in paper after viewing (59.39\%), instead of using a word processor (43.57\%), or a specific app (6.96\%).

From an ethical approach to information management the answers show that the majority of the subjects use references $(83.35 \%)$ and respecting author rights avoiding plagiarism $(67.48 \%)$

\section{Learning Process Management}

Data were collected using items related to the following dimensions: self-regulation and planning, critical thinking open learning, attention and problem solving.

The majority of participants do not use ICT to manage the knowledge (less than $19 \%$ in any case) so they do not use tools as calendar, time lines, knowledge management tools or collaborative environments. The schedule is on a traditional personal diary made of paper. And they are not worried about the impact of their work on the Internet.

The percentage of students who prefer studies in virtual modality is a minority, so they prefer face-to-face studies $(50.93 \%)$. Some of them have information about MOOC, but in general this type of courses are not still well known among Spanish university students.

When the subjects search information and use it, the currently is more important than the esthetic aspects of the presentation $(31.63 \%)$. They also value the clarity of the information $(44.65 \%)$. 
Uses of social tools and open resources on the net are not very frequent, thus the students like to ask to their own social net of personal contacts.

\section{Communication}

Finally the survey included items about communication with other people and group work. As we are explaining, the participants do not use social nets frequently. Students are familiar with more traditional telematic tools as email or messenger. They do not use either videoconferences or chat. But all students use Google Drive to collaborate on line.

\section{DISCUSSION, CONCLUSION AND FUTURE WORK}

As a summary of these first results we can conclude an interesting view about how our senior Spanish students learn. This interest in PLE put all our attention in a student-centered approach that emphasizes the learning strategies and tools as principal variables of final academic results and also permits us analyze the competences of our students from the long-life learning perspective [18], [24].

In our opinion the main advantage of this project is firstly the mixed method to obtain the validated questionnaire; and secondly the sample, that is enough important $(n=2054)$ to permit us building a real and interesting framework about the Personal Learning Environments with all data obtained in our research.

This is only a brief extract of our first results and we have to continue analyzing them from a deep approach during the last year of the project. But one key idea is arising with these data: although we are used to read about digital natives, the reality is so different. In recent years this concept of digital natives [14] has been used frequently to describe our current students [25], [26]. But our research is really far from this vision of the university students.

Data obtained in our survey draw a profile very different of the digital alphabetized people in Information and Communication Era. So they are in fact traditional students who like work with paper and are overall users of the Internet to search for contents but they do not create or share. Just opposite to the vision of them that authors cited above have.

Furthermore in same sense other researchers [27], [28] conclude that students like to collaborate and share information whit peers. These authors find students motivated and also engaged with collaboration, students who develop self-regulated learning supported on digital technologies and on Internet. According to this vision, in another experience in higher education [29] it is possible to find students who are making the best "searching, aggregating, creating and sharing content and learning resources, and being engaged in online learning networks and communities".

Unlike these works, our research show a very different reality: the majority of our Spanish students do not like digital tools when they are really studying, they do not use social nets to learn and finally they are not used to share contents on the net, hence they prefer search and use contents that they find.

Perhaps these significant differences between our results or research ant the other that we have mentioned could be given because we ask students how they learn and what tools they use. Other researchers prefer evaluate experiences design to implement new strategies and tools in order to demonstrate that students like and learn with them. But the question could be the difference between the self-regulated learning context or the mediated and guided by teachers learning.

Our results support the findings of [30] in a research also developed with university students: "The findings confirm that the students of this course illustrated poor capability when incorporating technology with learning. Furthermore, it is unexpected that the students faced much anxiety and stress using technology even though they are from the net generation". All these results seem to be consistent with other research [31], which found nor students or teachers use social media for educational purposes.

This conclusion is also consistent with [32] focused in law studies. They conclude that law students prefer traditional learning environment instead of non-traditional ones because of familiarity, self-efficacy and employment status.

Other open field of research is the interoperability between PLE and VLE (Virtual Learning Environments) as [33] remarks in their study. Institutional learning management systems have to interact and exchange information with tools of the student's PLE [34]. Thus our data can be useful to build a scenario near to the real uses of telematic tools by university students and to help them in self-regulated learning processes adopting a real active role [35], [36].

In the end all these studies open a new field of research which conclusions can undoubtedly be really relevant for teachers, students and institutions of higher education in the future. And moreover it is certainly possible to agree that "PLEs provide the new level of learning that is required by the new type of learners" [27] and "education is entering a period of radical discontinuity" [28].

Thus our exploratory research open a framework to develop future works where we could analyze these data in depth, but also we could compare and test our conclusions with other samples of population and in another contexts of research. It could be also interesting to test the vision of teachers about this PLE picture we have drawn and their own digital competence to develop the students' PLE in the way of digital education for learners in the ICT Era.

\section{APPENDIX}

More information about this project is on the web site: http://www.um.es/ple

\section{ACKNOWLEDGMENT}

Authors of this article sincerely thank to all the researchers from Spanish universities that have collaborated in collecting data and with students that have participated directly in the survey. Additionally it is remarkable the role of the other researchers involved in the CAPPLE Project, specially the Research Group of Educational Technology at the University of Murcia (GITE), without which it would have been impossible to make all this work.

\section{REFERENCES}

[1] C. Costa, "Lifelong learning in Web 2.0 environments," International Journal of Technology Enhanced Learning, vol. 2, no. 3, pp. 275-284, 2010.

[2] G. Attwell, "Personal learning environments-the future of elearning?" eLearning Papers, vol. 2, no. 1, pp. 1-7, 2007 
[3] I. Buchem, G. Attwell, and R. Torres-Kompen, "Understanding personal learning environments: Literature review and synthesis through the Activity Theory," presented at the PLE Conference 2011, July 2011, Southampton, UK

[4] L. Castañeda and J. Adell, Personal Learning Environments: Keys to the Ecosystem of the Educational Network. Alicante: Marfil, 2013.

[5] B. Kieslinger and D. Gillet, "How social is my personal learning environment (PLE)? Part 1," in Proc. World Conference on Educational Multimedia, Hypermedia and Telecommunications 2008 , 2008, pp. 4984-4989.

[6] S. Fiedler, "Getting beyond centralized technologies in higher education, Part 1," in Proc. World Conference on Educational Multimedia, Hypermedia and Telecommunications 2007, 2007, pp. 1340-1346.

[7] C. Severance, J. Hardin, and A. Whyte, "The coming functionality mash-up in Personal Learning Environments," Interactive Learning Environments, vol. 16, No. 1, April 2008, pp. 47-62.

[8] S. Waters, "Here are the results from my PLN survey!" 2008.

[9] U. Daniels and R. Carneiro, "Personal learning environments," E-learning Papers, vol. 9, no. 2, 2008.

[10] G. Attwell and C. Costa, "Integrating personal learning and working environments," Beyond Current Horizons, 2009.

[11] L. Castañeda, C. Costa, and R. Torres-Kompen, "The madhouse of ideas: Stories about networking and learning with twitter," presented at the PLE Conference 2011, July 2011

[12] J. Adell and L. Castañeda, "The personal learning environments (PLEs): A new way of understanding learning," Keys for the Research in Educational Innovation and Quality. The Integration of the Information Technologies, the Communication, and the Multiculturalism in the Classroom.

[13] G. Attwell, Personal Learning Environments: The Future of Education? 2008.

[14] M. Prensky, "Digital natives, digital immigrants," On the Horizon, MCB University Press, vol. 9, no. 5, October 2001.

[15] D. White and A. L. Cornu, "Visitors and Residents: A new typology for online engagement," First Monday, vol. 16, no. 9, 2011.

[16] P. Prendes Espinosa, L. Castañeda, and I. Gutiérrez, "How do professionals learn? Designing and validating an instrument for describing the personal learning environments (PLEs) of the last year university students," in Proc. World Conference on Educational Media and Technology Ed-Media 2014, 2014, pp. 204-211.

[17] P. P. Espinosa and L. Castañeda, "PLE-centered education: The next boundary. Perceptions and realities behind students personal learning environments," ELA Journal of Educational Leadership in Action, Chicago, Illinois, vol. 2, no. 1, 2013, pp. 3-12.

[18] P. P. Espinosa, "CAPPLE: Exploring the PLE of the future professionals," Personal Learning Environments: Keys to the Ecosystem of the Educational Network, pp. 173-176.

[19] J. H. McMillan and S. Schumacher, Research in Education: A Conceptual Introduction, 5th ed., New York: Longman, 2001.

[20] A. Tashakkori and C. Teddlie, Handbook of Mixed Methods in Social and Behavioral Research, Thousand Oaks: Sage, 2003.

[21] P. Newby, Research Methods for Education, Essex: Pearson, 2010.

[22] D. Dillman, Mail and Internet Surveys the Tailored Design Method, New Jersey: John Wiley \& Sons, Inc, 2007

[23] F. D. Cerbo, G. Dodero, and L. Papaleo, "Experiencing personal learning environments and networks using a 3D space metaphor," Interaction Design and Architecture(s) Journal - IxD\&A, 2011, pp. 64-76.

[24] B. Tabuenca, M. Kalz, and M. Specht, "Tap it again, sam: Harmonizing personal environments towards lifelong learning," International Journal of Advanced Corporate Learning (iJAC), vol. 8, no. $1,2015$.

[25] S. Dávila, "Generación net: Visiones para su educación," ORBIS, no. 3 , 2006, pp. 24-48.

[26] F. García, J. Portillo, J. Romo, and M. Benito, "Digital natives and learning models," presented at IV Multi-disciplinary Symposium on Design, Evaluation and Development of Reusable Educational Content Bilbao, Sep. 2007.

[27] P. Panagiotidis, "Personal learning environments for language learning," Social Technologies Research Journal, vol. 2, no. 2, pp. 420-441, 2012

[28] P. W. Conradie, "Supporting self-directed learning by connectivism and personal learning environments," International Journal of Information and Education Technology, vol. 4, no. 3, 2014

[29] M. Saadatmand and K. Kumpulainen, "Content aggregation and knowledge sharing in a personal learning environment: Serendipity in open online networks," International Journal of Emerging Technologies in Learning, vol. 8, pp. 70-77, 2013.

[30] P. Krish, N. Zabidi, and N. Mohd, "Creating personal learning environments via blogs," Advances in Language and Literary Studies, vol. 4, no. 2, 2013.

[31] B. Chen and T. Bryer, "Investigating instructional strategies for using social media in formal and informal learning," The International Review of Research in Open and Distributed Learning, vol. 13, no. 1, 2012.

[32] D. C. Auld, F. C. Blumberg, and K. Clayton, "Linkages between motivation, self- efficacy, self-regulated learning and preferences for traditional learning environments or those with an online component," Digital Culture \& Education, vol. 2, no. 2, pp. 128-143, 2010.

[33] F. J. García-Peñalvo, M. C. González, M. Alier, and R Colomo-Palacios, "A case study for measuring informal learning in PLEs," International Journal of Emerging Technologies in Learning, vol. 9, no. 7, 2014

[34] B. Taraghi, M. Ebner, G. Till, and H. Mühlburger, "Personal learning environment? A conceptual study," International Journal of Emerging Technologies in Learning, vol. 5, 2010.

[35] J. C. Almenara, "The self-regulated learning as a theoretical framework for the educational application of the virtual communities and personal learning environments," Education in the Knowledge Society, vol. 14 no. 2, 2013.

[36] M. C. L. Cejudo, "Assessing personal learning environments (PLEs). An expert evaluation," NAER, Journal of New Approaches in Educational Reserch, vol 2, no. 1, 2013.

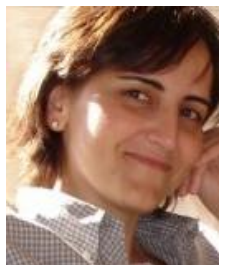

Paz Prendes was born in Cartagena, Spain, 1967. She is a $\mathrm{PhD}$ in sciences of education in 1994 with extraordinary award and university expert in educational technology. She is a professor of the Department of Didactics and School Organization and also the head of the Research Group about Educationa Technology at the University of Murcia (Spain). She is a coordinator of both the "Master in educational

technology: E-learning \& knowledge management" and also the "PhD program in educational technology" at the University of Murcia.

She has been working at the University of Murcia since 1990 when she finished her degree in sciences of education with a national award. She has published books as "Nuevas Tecnologías y Educación" (Madrid: Pearson, 2004) or "Las TIC en las Aulas Hospitalarias" (Alicante: Marfil, 2012) and articles about e-learning, digital competence, instructional design, semantic web, collaborative learning, MOOC and uses of technologies in education in general.

Prof. Prendes is also the secretary of Edutec, International and Professional Association to promote Educational Technology and New Technologies in Education. She is a reviewer of Pixel-Bit, NAER or Educación XXI among others

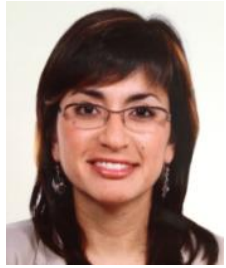

Linda Castañeda is an assistant professor in educational technology in the Department of Didactics and School Organization at the University of Murcia (Spain). She is also one member of GITE (group of research in educational technology) .She is educationalist from the University of Murcia and the $\mathrm{PhD}$ in educational technology by the University of Balearic Islands (Extraordinary Doctorate Award and

European Mention)

She has spent some periods of working in research visiting at the Knowledge Media Institute at the Open University of UK, The Group of Research in e-learning of the University of Oxford, and the Centre for Education and New Technologies (CENT) from the Universitat Jaume I of Castellon (Spain). With her background in educational technology, she has participated in national and international research projects centred on the use, integration and evaluation of information and communication technologies in education, e-learning, and the impact of those on the social, curricular and organizational change. Currently, her research is around web 2.0 in education and training, personal learning environments and emergent technologies and pedagogies.

Dr. Castañeda has participated in a wide variety of international events as speaker and she has published some books and papers in specialized journals and conferences. She teaches in degrees related to education. She is lecturing at the Faculty of Education, in the degrees of pedagogy, social education, future primary school teachers, and also in the masters of technology enhanced learning. 


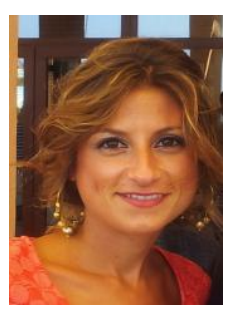

Isabel Gutiérrez was Murcia, Spain, in 1984. She got the degree in pedagogy at the University of Murcia (Spain) in 2007 and the master in e-learning. Educational technology and knowledge management at the University of Balearic Islands (Spain) in 2008 and the $\mathrm{PhD}$ in educational technology at the University Rovira I Virgili (Tarragona, Spain) in 2011. Her field of study is educational technology.

She is assistant professor in educational technology in the Department of Didactics and School Organization at the University of Murcia (Spain). She is also one member of the Group of Research in Educational Technology (GITE) at the University of Murcia. She teaches in degrees related to education. She is lecturing at the Faculty of Education, in the degrees of social education, future primary school teachers, and also in the masters of technology enhanced learning. She is an author of the book Digital Educative Resources (Madrid, Spain: Síntesis, 2010). She is author of some important book chapter like Social Networks and other spaces online to connect people (Sevilla, Spain: MAD, 2010), Analysis Model of the ICT competence of the University Teachers (Alcoy, Spain: Marfil, 2011) She has participated in national and international research projects centered on the use, integration and evaluation of Information and Communication Technologies in Education; social networks, ICT in the Hospital Classrooms, Personal Learning Environments, etc. Also, she has spent some periods of working in research visiting at the Massachusetts Institute of Technology (Massachusetts, USA), Trinity College (Dublin, Ireland), National University of Ireland (Galway, Ireland).

Dr. Gutiérrez got the honor degree in Pedagogy and Extraordinary Award in Pedagogy in Spain. Also, she got the Extraordinary Doctorate Award. Dr. Gutiérrez is one member of EDUTEC (Society for the Develop of the Educational Technology).

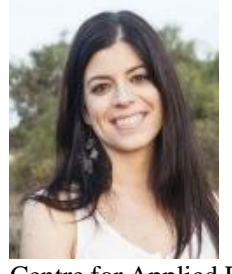

M. Mar Sánchez was born in Cartagena, on October 18 in 1982. She ended in 2006 the degree in pedagogy, at the Faculty of Education in Murcia, Spain. In 2007 she got a fellowship in the National Institute of Educational Technology at the Ministry of Education in Madrid. Spain. From 2008 to 2010 she worked as $\mathrm{PhD}$ student at the University of Murcia. She also had collaborated in 2008 with a research fellowship at the Centre for Applied Research in Educational Technology at the University of Cambridge (UK) and in 2013 in the Centre for Innovation in Technologies and Education (CITE) at the University of Southampton (UK)

Currently, she is senior lecturer at the University of Murcia (Spain), in the Department of Didactics and School Organization. She teaches in degrees related to education, like pedagogy, social education, elementary teachers and kindergarden teachers. And she is also in the master of technology enhanced learning.

She had published several book, chapters papers related with her research experience in education and technology. Some examples are "Web Semántica: aplicaciones prácticas para la educación" (Madrid: Dykinson, 2012), the article "Beyond objective testing and peer assesstment: alternative ways of assessment in MOOCs" in RUSC, Vol 12. (2015), or at leas "Challengues in the creation, development and implementation of MOOCs: Web Science at the University of Southampton", in Comunicar, 44 (2015) Her research experience and current interest is related with Semantic Web, MOOCs, social networks and, in general, the use of technology in educational environments. 